\title{
Retos de la industria: Banca Tradicional vrs Fintech
}

\section{Para empezar, ¿Qué es Fintech?}

Se trata de un nuevo concepto de negocio que revoluciona el mercado financiero a escala mundial, ya que define a aquellos servicios financieros que usan la tecnología para facilitar la vida al cliente y mejorar la experiencia de usuario. Es decir, créditos online, cambio de divisas a través de la red, pagos online, banca digital, entre otros servicios.

\section{Beneficios de las Fintech}

$73 \%$ eficiencia y
reducción de
costos
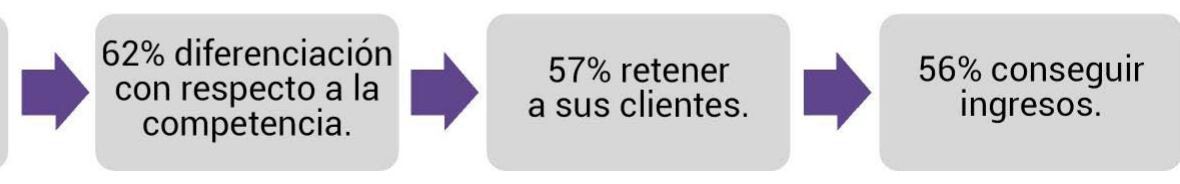

Las empresas fintech han demostrado que existe otra forma de gestionar el dinero de los clientes, una forma más veloz, cómoda y transparente. Su fortaleza consiste en ofrecer soluciones más rápidas, con menos recursos y empleando menos dinero.

\section{Retos}

Las gestiones más rápidas y automatizadas mejoran la eficiencia empresarial. Una eficiencia que se traduce, concretamente en el caso de las fianzas, en ahorro económico.

\section{EFICIENCIA:}

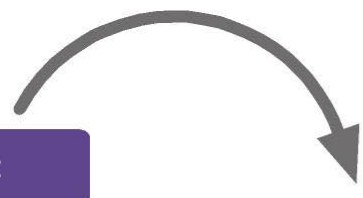

La tecnología financiera es y nos hace más eficientes. La automatización supone una gran especialización ya que ofrece servicios muy concretos.
A través de esta tecnología aplicada a las finanzas la empresa puede gestionar de una manera transparente y rápida. De este modo, Fintech se convierte en sinónimo de transparencia.

\section{FLEXIBILIDAD:}

Este tipo de tecnología construye nuevos flujos de trabajo más ágiles. Por tanto, permiten guardar datos, hacer operaciones a través de una financiación alternativa y mucho más; donde y cuando se quiera.

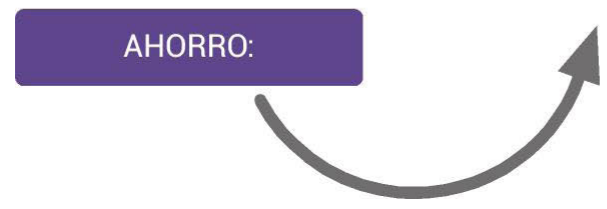

TRANSPARENCIA: 


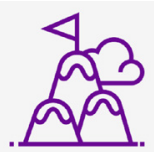

Retos de Fintech

Adecuación regulatoria

- Comunicación: Falta de acercamiento entre actores claves, reguladores, sector financiero y Fintech

- Regulación: Las regulaciones no avanzan en forma paralela a la innovación del sector

- Entorno jurídico: El entorno actual limita el establecimiento y alcance de los emprendimientos Fintech

Falta de acceso al mercado de capitales

- Las opciones de capital de riesgo y los mercado de valores son muy poco profundas.

- Inversionistas: Los emprendimientos acaban dependiendo de inversionistas externos o familyoffices.

- Nuevas Tecnologías: importante impulsar el apalancamiento en nuevas tecnologías que permitan la apertura de nuevas vías de financiamiento sencillas y claras.

Fuente: Ticbeat.com

\section{¿Cómo se percibe actualmente la banca tradicional?}

Los altos costos de acceso, las elevadas tasas de interés, la falta de productos y servicios que aporten valor a los usuarios, y la complejidad de uso son los principales factores que hacen de la industria financiera una de las menos apreciadas por los usuarios, sobre todo en regiones como América Latina y el Caribe.

El $71 \%$ de los millennials prefiere ir al dentista antes que interactuar con su banco, y la mayoría no sabe identificar las diferencias entre su banco y otro.
Unos 210 millones de personas, equivalentes al $46 \%$ de la población adulta, no tienen una cuenta bancaria.

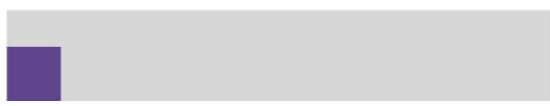

El $33 \%$ de los millennials creen que no necesitan un banco.

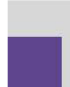

Otras desventaja es que las instituciones financieras que operan de manera tradicional siguen protocolos burocráticos que suelen tomar varios días, sino es que semanas.

En el caso de los préstamos personales brindados por los bancos, las solicitudes se evalúan exhaustivamente durante días antes de dar una respuesta.Aunado a los lentos procesos hay que considerar que la mayoría de los bancos trabaja de lunes a viernes de 8 a 3 de la tarde. Por el contrario, las financieras tecnológicas operan $24 / 7$ con una capacidad de respuesta que va desde unos minutos hasta un día comomáximo. 


\section{Retos de la banca tradicional}

De acuerdo con un estudio realizado por Juniper Researchen 2017, el uso de la banca digital aumentará de manera continua por lo que los bancos tendrán que preocuparse por garantizar una experiencia digital cada vez más cómoda a sus clientes.

El estudio también indica que mientras que los bancos tradicionales han permanecido un paso atrás en innovación y en mantener su ventaja competitiva frente a los nuevos jugadores 'fintech', la situación está cambiando.

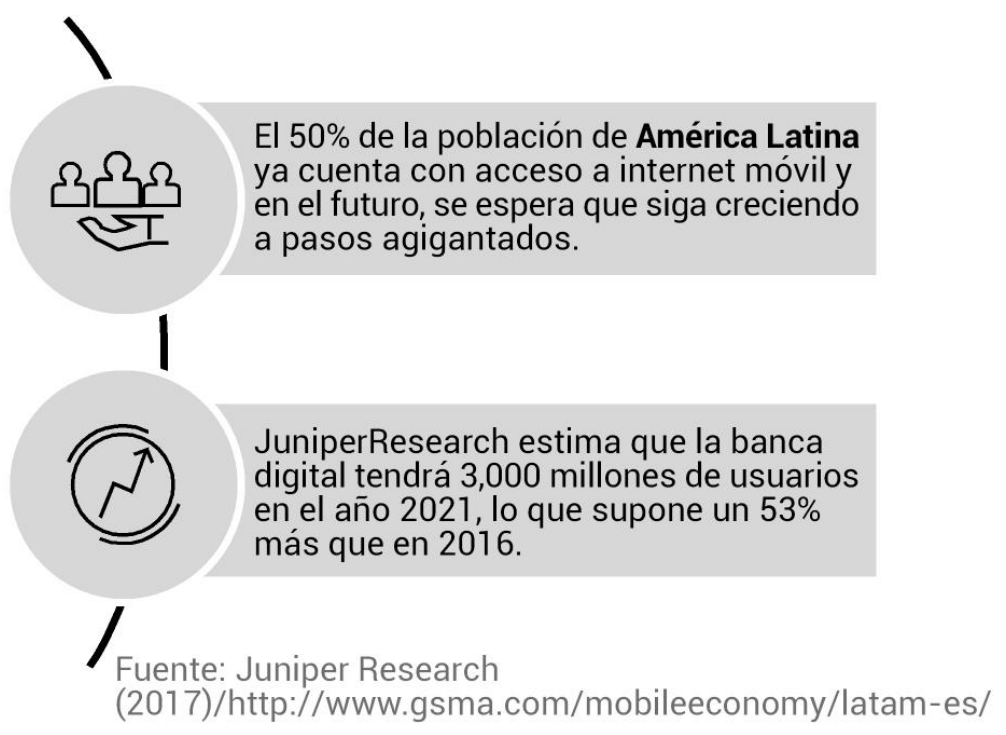

\section{Extra: Fintech en la región:}

En Centroamérica, Panamá y República Dominicana se registran 30 fintech en total, en situación de "startup" y que no están vinculadas a ningún desarrollo o iniciativa del sistema bancario.

\section{Distribución por segmentos Fintech (en términos de número de emprendimientos)}

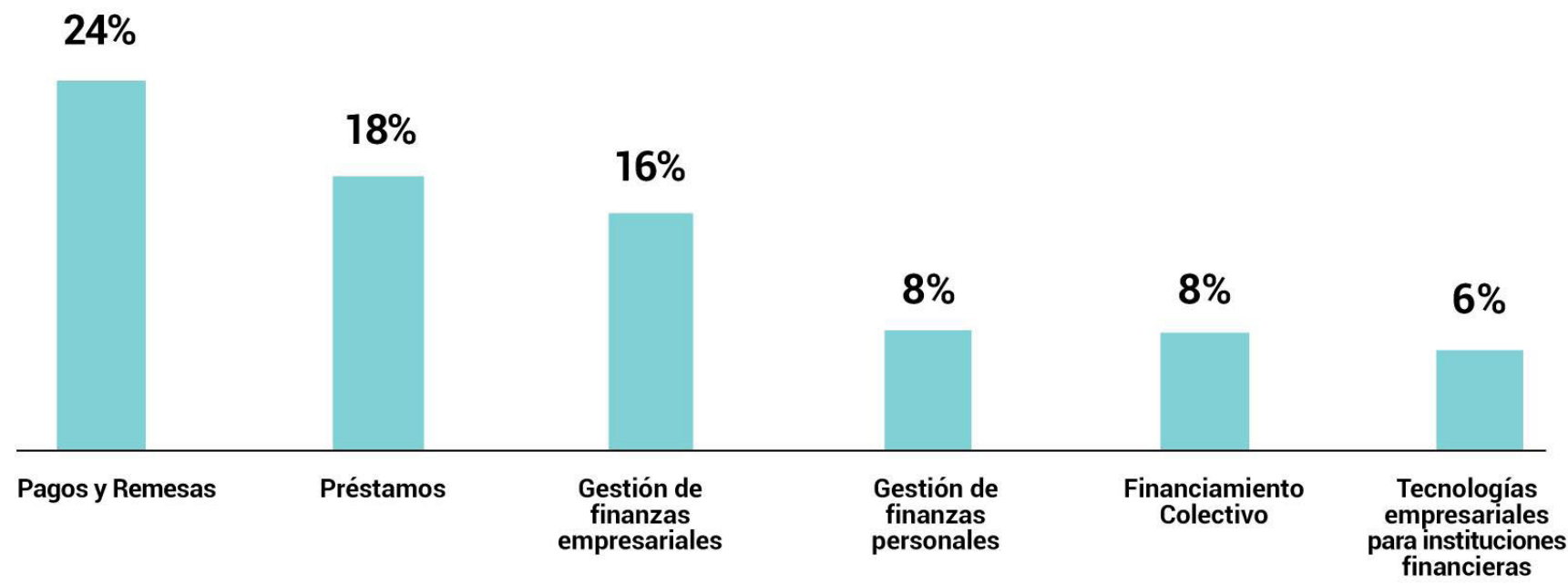




\section{Iniciativas de Fintech en la Región \\ (Startups)}

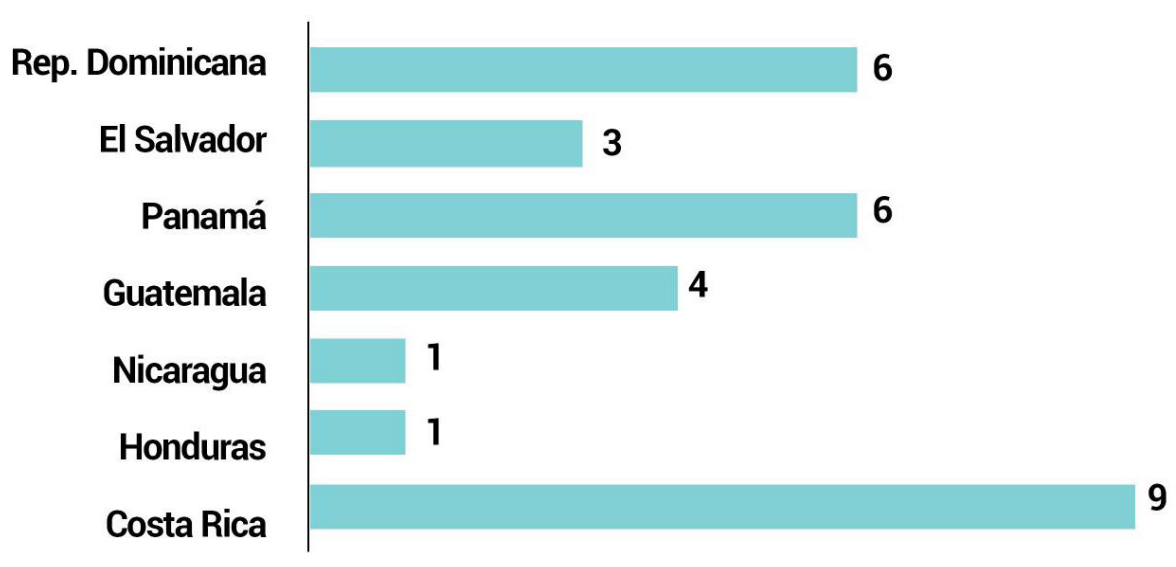

En cuanto a la industria Fintech, en América Latina y el Caribe es todavía una industria muy nueva y será necesario que tanto el sector público como el privado trabajen juntos para promocionar su consolidación y crecimiento.

\section{Better begins now $\mathbf{~} \mathbf{Z}$}




\section{EY | Assurance | Tax | Transactions | Consulting}

\section{Acerca de EY}

EY es un líder global en servicios de auditoría, impuestos, transacciones y consultoría. Nuestro conocimiento, puntos de vista y servicios de calidad ayudan a generar confianza en los mercados de capital y en las economías alrededor del mundo.

Desarrollamos líderes excepcionales que trabajan en equipo para cumplir las promesas hechas a todos nuestros grupos de interés. Al hacerlo, desempeñamos un papel fundamental en la construcción de un mejor mundo de negocios para nuestra gente, nuestros clientes y nuestras comunidades.

EY se refiere a la organización global de firmas miembro conocidas como Ernst \& Young Global Limited, en la que cada una de ellas actúa como una entidad legal separada. Ernst \& Young Global Limited, compañía del Reino Unido limitada por garantía, no provee servicios a clientes. Más información en www.ey.com.

(C) 2018 E\&Y Central America Inc.

Todos los derechos reservados.

Esta publicación contiene información en forma de resumen y, por lo tanto, su uso es solo para orientación general. No debe considerarse como sustituto de la investigación detallada o del ejercicio de un criterio profesional. Ni E\&Y Central America Inc., ni ningún otro miembro de la organización global de EY acepta responsabilidad alguna por la pérdida ocasionada a cualquier persona que actúe o deje de actuar como resultado de algún contenido en esta publicación. Sobre cualquier asunto en particular, referirse al asesor apropiado.

ey.com

\section{(D CONTÁCTENOS}

Luis E. Artavia Gutiérrez Socio Director de Transacciones Centro América y República Dominicana (506) 2208-9800 luis.artavia@cr.ey.com

Gustavo A. Ortiz Madrigal

Director de Infraestructura y Project Finance Centro América y República Dominicana (506) 2208-9802 gustavo.a.ortiz@cr.ey.com 